\title{
Undue credit for supervisors
}

SIR - As a postgraduate completing a PhD and enjoying an excellent working relationship with my supervisor, I am concerned about the pressure that many departments, in many universities, are placing on research students to include their supervisors' names at the top of journal papers, regardless of whether the supervisors have made contributions to the authorship of the publications.

Although many research students choose to share the authorship of their research publications with their supervisors, it is by no means a universal practice. The last Research Assessment Exercise (RAE), however, has caused many UK university departments to sacrifice intellectual freedom for the sake of their positions in the research league. Under the terms of the last RAE, which sought to assess the research output of staff funded by the Higher Education Funding Council (HEFC), when a student publishes the results of his or her research, the department cannot include the paper in its list of publications unless a member of staff is a co-author.

In many cases, the contribution of a supervisor to a student's research is correctly acknowledged by co-authorship on papers. But the primary role of a supervisor is as an overseer and trainer, not as a co-worker. Such an input is more appropriately recognized in the acknowledgements at the end of a paper, together with the research student's grant number and the name of the sponsor. The last RAE, however, ignored the fact that the supervision of research students is, even without co-authorship, a significant and substantial part of the research output of university staff.

Desperate to boost their ratings, a number of departments are now insisting that supervisors ensure that their names appear on all of their students' papers. One consequence may be that supervisors will be able to veto any papers with which they are unhappy, whether they dislike the style of the science, the writing, or even the prospect of a research student receiving sole credit for work that may have been undertaken with only minimal supervision. The corridors of our universities already echo with rumours of supervisors who have stolen their students' ideas and data to publish as their own.

Surely the freedom to submit the results of their research for publication, with or without their supervisors' blessing, is an important prerogative for research students who have to demonstrate independence of thought to obtain their doctorate?

Indeed, is it not an act of scientific fraud to claim co-authorship for a research publication when one has not produced any of the ideas or data contained in a paper? Even if no-one else cares, the editors of journals must be concerned by such a practice.

There is one very easy way for the HEFC to remove the cudgel that is currently being waved above the head of research students. In the next RAE, why not allow research students' publications to be included even when not co-authored by their supervisors? Without a change in the approach to the RAE, research students will continue to be regarded as mere pawns in the financial squabbling between university departments and the HEFC, rather than as the independent, wealthcreating scientists of tomorrow.

\section{Bob Ward}

Flat 1, 6A Old Lansdowne Road,

West Didsbury,

ManchesterM20 2NU, UK

\section{In the eye of the beholder?}

SIR - I was fascinated, but somewhat flummoxed, by the recent contribution by Perrett et al. addressing facial shape and judgements of female attractiveness (Nature $368 ; 239-242 ; 1994)$. My problem is that in these days of political correctness, when we males are supposed to be fighting energetically against any biologically or at least constitutionally driven tendencies towards differential treatment of individual women (at least in the workplace), I am unsure whether to be challenged (the old me) or relieved (the new politically correct me) at being scarcely able to distinguish from one another the computer-reconstructed faces from within the two sets offered. In view of the severity of the effective selection process said to have resulted in, particularly, the third face of each set in relation to the first, is this not (or perhaps, am I as heterosexual male not) rather singular? While being able with study to see the differences, I certainly could not remember and attach differential names to faces within each set, and therefore cannot readily imagine developing differential feelings towards their owners on this basis alone.

Does my bluntness of conscious perception in this matter mean I am a victim of some high-order neurological condition, to be named in the appropriate textbooks alongside (if I remember rightly) prosopagnosia? I would welcome access to a small sample of other readers' personal findings. Alternatively, the theory might be that such differential perceptions can exist and exert their effects on behaviour, while by-passing altogether the consciousness of the perceiver. There are certainly disturbing precedents for this, and yet the 'attractive' subset of primary data faces was selected by conscious processes. I suspect an important reality is that in real situations other differentials of women's total 'output' (appearance and behaviour combined), possibly through equally constitutionally mediated and thus politically problematic mechanisms, tend to have greater valency and to wipe out the contributions of all but extreme excursions from the norms of facial proportion to attractiveness ratings.

\section{J. Cooke}

National Institute for Medical Research, Mill Hill,

London NW7 1AA, UK

\section{Leprosy vaccine}

SIR - In a News report describing a dispute between Indian scientists about candidate vaccines against leprosy ${ }^{1}$, reference was made to work from our laboratory as establishing the identity of the vaccine strains. This is not accurate. In 1989 we published a report ${ }^{2}$ describing the first repetitive DNA element in Mycobacterium leprae located adjacent to the $h s p$ 60 gene that had then recently been cloned. The paper shows that the insertional element was found only in $M$. leprae and not in six other mycobacteria, including the two Indian candidate vaccine strains with which we were kindly provided. Hence the repetitive element was not useful for studying polymorphisms in other mycobacterial species by DNA fingerprinting. The paper did show, however, hybridization bands to the hsp 60 antigen found in all mycobacteria, and that the sizes of the DNA restriction fragments containing the gene were similar for the two Indian vaccine strains. However, this does not establish identity, as the number of bands in the patterns was small (only 2 or 3 ) and the $h s p$ gene is highly conserved.

Since our publication, a number of mycobacterial genes have been sequenced, and several repetitive insertional sequences have been identified. With these new tools, it should readily be possible for an independent laboratory to establish definitively, by multiple parameter analysis, the identity or nonidentity of the disputed strains.

\section{Barry R. Bloom}

William R. Jacobs Jr

Howard Hughes Medical Institute, Albert Einstein College of Medicine,

Bronx, New York 10461, USA

Josephine E. Clark-Curtiss

Department of MolecularMicrobiology, Washington University,

St Louis, Missouri 63130-4899, USA

1. Nature 367, $403(1994)$

2. Grossinsky, C. M. Jacobs, W. R. Jr, Clark-Curtiss, J. E. \& Bloom, B. R. Infect. Immun. 57, 1535-1541(1988). 